\title{
Sensitivity studies of the $E$ region neutral response to the postmidnight diffuse aurora
}

\author{
H. F. Parish and L. R. Lyons \\ Department of Atmospheric and Oceanic Sciences, University of California Los Angeles, Los Angeles, CA 90095-1565, USA
}

Received: 10 August 2005 - Revised: 6 April 2006 - Accepted: 15 May 2006 - Published: 3 July 2006

\begin{abstract}
Measurements of the neutral thermosphere within the postmidnight substorm recovery phase diffuse aurora show very large horizontal winds, and strong vertical structure. Rocket, satellite, and ground based observations during the ARIA (Atmospheric Response in Aurora) campaigns, and earlier dawn side rocket observations, indicate neutral winds of up to $200 \mathrm{~m} / \mathrm{s}$, and a characteristic jet-like wind maximum around 110 to $120-\mathrm{km}$ altitude, with strong shears above and below. The observed wind magnitudes are found to have a dependence on geomagnetic activity level, but recent modeling studies suggest that tides which propagate up from the troposphere and stratosphere may play an important role in generating the strong vertical variations in the neutral winds. The relative importance of auroral and tidal forcing in producing the measured wind structure is not known, however. Simulations have been performed using a three dimensional (3-D) high resolution limited area thermosphere model to understand the processes which generate the observed neutral structure within the postmidnight diffuse aurora. Parameters measured during the ARIA I observational campaign have been used to provide auroral forcing inputs for the model. Global background winds and tides have been provided by the CTIP (Coupled Thermosphere Ionosphere Plasmasphere) model. The sensitivity of the response of the neutral atmosphere to changes in different parameters has been examined. Variations in the amplitudes and phases of the propagating tides in the background winds are found to have significant effects on the neutral structure in the $E$ region, and the wind structure below around $110 \mathrm{~km}$ is found to be mainly produced by tidal forcing. Changes in the electric field and ion density affect the winds above around $120 \mathrm{~km}$, and the importance of auroral forcing is found to depend on background winds. Variations in the orientation of the aurora relative to the background field, which may be
\end{abstract}

Correspondence to: H. F. Parish

(helen@atmos.ucla.edu) caused by changes in the interplanetary magnetic field, are also found to modify the wind structure. When both auroral forcing and propagating tides are included, many of the basic characteristics of the wind structure are displayed, although the great strength of the wind shears is not well reproduced. The strength of the shears may be related to a currently unmodeled process, or to different types of waves.

Keywords. Meteorology and atmospheric dynamics (Thermospheric dynamics; Waves and tides) - Magnetospheric physics (Auroral phenomena)

\section{Introduction}

Observations of $\mathrm{E}$ region neutral winds in the postmidnight sector at high latitudes have been found to show large magnitudes of more than $200 \mathrm{~m} / \mathrm{s}$ (e.g. Johnson et al., 1987). Measurements of neutral structure within the postmidnight diffuse aurora during the ARIA (Atmospheric Response in Aurora) coordinated rocket, ground based and satellite campaigns (Anderson et al., 1995; Larsen et al., 1995), and earlier rocket campaigns (Larsen et al., 1989) show strong vertical structure in the winds, with peak magnitudes of around $200 \mathrm{~m} / \mathrm{s}$ between 110 and $120-\mathrm{km}$ altitude, and large wind shears above and below. The shear below the peak sometimes appears to be unstable, with Richardson number less than 0.25. Even larger $\mathrm{E}$ region winds, of around 350 to $400 \mathrm{~m} / \mathrm{s}$ at $30-\mathrm{km}$ altitude, have been observed during rocket campaigns within the aurora on the premidnight side (Mikkelsen et al., 1987, 1981). The postmidnight diffuse aurora will be investigated here, which may have brighter emissions than the premidnight diffuse aurora due to the larger precipitating electron energy fluxes, resulting from the tendency of plasma sheet electrons to drift towards the dawn side (Wing and Newell 1998; Wang et al. 2001). This larger precipitation will result in increased $\mathrm{E}$ region ion densities,

Published by Copernicus GmbH on behalf of the European Geosciences Union. 


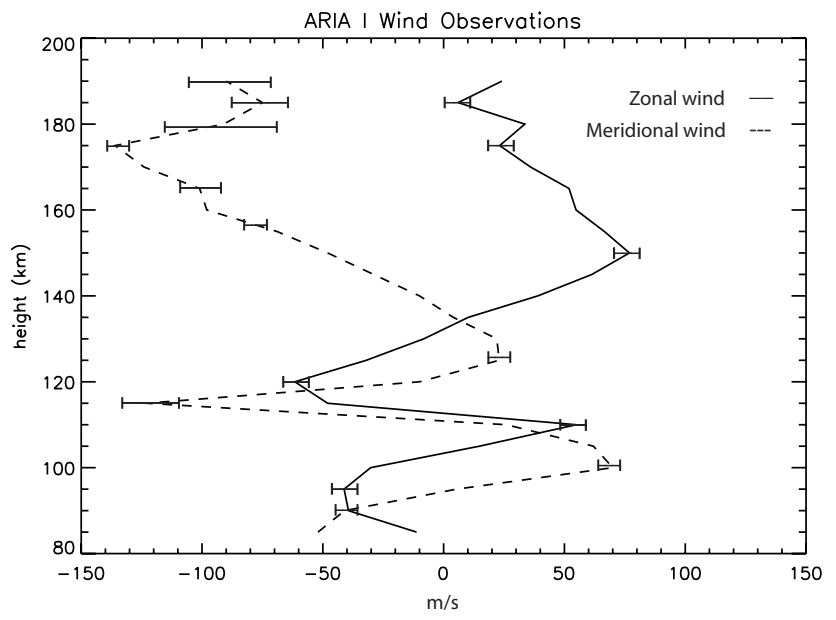

Fig. 1. Neutral winds observed during the ARIA I Campaign on 3 March 1992.

enhanced coupling to the neutrals, and enhanced Joule heating. However, the presence of $\mathrm{E}$ region winds of the observed magnitudes is not well explained in terms of auroral acceleration processes alone. The mechanisms which generate this strong vertical structure are not completely understood, and the dynamical impact of the strong winds and shears and the effects of their dissipation on the neutral atmosphere and the general circulation are not well known. The enhanced auroral precipitation and electric fields at high latitudes associated with the diffuse aurora may have impacts at lower latitudes, as well as in the auroral zone, and may cause composition changes (Parish et al, 1994), and generate gravity waves which propagate to lower and higher latitudes (Parish et al., 1997; Walterscheid and Lyons, 1989; Richmond and Matsushita, 1975). In this work we investigate the factors that affect the $\mathrm{E}$ region neutral winds in the region of the postmidnight diffuse aurora.

The origins of the strong vertical structure which is observed are not well known, but may be associated with the effects of auroral forcing or the influence of background winds. Within the diffuse aurora the neutral winds are driven by ion drag forcing and Joule heating, which depend on the magnitude and structure of ion densities and electric fields. These ion densities and electric fields are enhanced within the diffuse aurora during periods of enhanced convection. The direction of the ion drag forcing varies with altitude in the E region, due to changes in densities and neutral-ion collisions, tending towards the direction of the electric field $\boldsymbol{E}$ at lower altitudes, and tending to follow the $\boldsymbol{E} \times \boldsymbol{B}$ drift direction (for magnetic field, $\boldsymbol{B}$ ) at higher altitudes. The changing magnitude and direction of auroral forcing with height during geomagnetic disturbances may therefore be a possible source of shears in the neutral wind profile. The acceleration of the neutral winds in the auroral region is also affected by the background winds. Cross arc winds tend to reduce the acceleration due to ion drag driven forcing, since each parcel of the neutral atmosphere spends less time within the region of acceleration if it is displaced by the cross arc wind (Walterscheid and Lyons, 1989; Fuller-Rowell, 1985). The effects of cross arc winds may vary with height due to changes in the direction of the background winds with altitude. One source of variation in the direction of the background winds with height could be propagating tides within the background winds. As propagating tides travel upwards the wind vector rotates, which may produce changes in the ion drag driven neutral flow with height, and may also help to generate shears.

Previously, two dimensional (2-D) models have been used to simulate the acceleration of neutral winds and small scale features in the auroral region (e.g. Fuller-Rowell, 1984; St. Maurice and Schunk, 1981; Richmond and Matsushita, 1975). However, features which vary rapidly in the zonal direction, such as the strong zonal winds and shears observed in the ARIA measurements, are not well simulated within 2D models. More recent simulations with 2-D models suggest that large neutral winds of around $200 \mathrm{~m} / \mathrm{s}$, and even supersonic winds, may be generated in the auroral zone (Walterscheid et al., 1985; Fuller-Rowell, 1985; Lyons and Walterscheid, 1985; Walterscheid and Lyons, 1989) although the magnitude of these winds could be reduced by the effects of cross arc winds. Brinkman et al. (1995) aimed to simulate the ARIA I observations using a high resolution 2-D model, making use of values measured during the campaign to give aurora forcing parameters, and they compared the simulated neutral winds with those observed during the campaign. The results of these simulations produced some general agreement with the observations, but the magnitudes, strong vertical structure and wind shears were not well reproduced.

Parish et al. (2003) suggested that propagating tides within the background wind field, which can be important in the E region at this latitude (Parish et al., 1990; Mikkelsen and Larsen, 1991), may have an important influence on the neutral wind structure within the region of the postmidnight diffuse aurora. The existence of a global component to the source of the observed vertical structure is suggested by rocket measurements at lower latitudes, which also show large winds and wind shears between around 100 and 120km altitude (Larsen, 2000; Yamamoto et al., 1998; Larsen et al., 1998). Parish et al. (2003) used ion density and electric field structures measured during the ARIA I campaign to provide auroral forcing inputs for a 3-D high resolution, limited area model, and compared the results of simulations with winds measured during the same campaign. The results showed much closer agreement with the ARIA I wind observations than previous attempts to simulate the winds from the same campaign (Brinkman et al., 1995). The results of Parish et al. (2003) suggest that higher order semidiurnal tidal modes such as the $(2,5)$ and $(2,6)$ modes (with tidal nomenclature as in Chapman and Lindzen, 1970) may be the most important in generating the observed vertical structures, 
and showed that the observed winds are not well reproduced if only auroral forcing processes are present. However, Parish et al. (2003) found that the best agreement with observations within the postmidnight diffuse aurora was produced by a combination of propagating tides and auroral forcing. Observations from the four ARIA campaigns also show that the wind maxima are larger when the geomagnetic activity level is higher (Larsen et al., 1997), suggesting that auroral forcing is important in producing the observed structure. In this paper we will examine the relative significance of propagating tides, and the effects of the electric field and ion density structures within the region of the diffuse aurora, in producing the observed neutral response.

Earlier investigations suggest that changes in the phases of the tidal variations in the background winds may be important (Parish et al., 2003). Several studies have generated climatologies for the amplitudes and phases of propagating tides in the thermosphere (e.g. Manson et al., 2002; Forbes et al., 1994; Forbes and Vial, 1991), but propagating tides show great day to day variability in amplitude and phase (e.g. Pancheva et al., 2000; Beard et al., 1999; Canziani, 1994; Phillips and Briggs, 1991), so the amplitude and phase of the tides for a specific day and location is not well known, in the absence of direct measurements. The sensitivity of the neutral response to these changes in the amplitudes and phases of the propagating tides in the background winds is therefore explored in this paper, as well as the sensitivity of the response to the time when propagating tides are introduced relative to the time at which the auroral forcing becomes important.

It is known that the strength and structure of the large scale convection at high latitudes can be strongly influenced by the orientation of the interplanetary magnetic field (IMF), as has been shown in many satellite and ground based investigations (e.g. Weimer, 1995, 1996; Holt et al., 1987; Heppner and Maynard, 1987). Changes in the high latitude convection pattern may influence the orientation of the auroral arc relative to the global scale background winds, and previous studies suggest that the magnitude of the neutral winds accelerated by auroral forcing can be significantly affected by the direction of the large scale background winds, depending on whether the winds are directed along or across the auroral arc (Walterscheid and Lyons, 1989; Fuller-Rowell, 1985). The effects of changes in the orientation of the aurora relative to the background wind field, such as those which may be caused by changes in the IMF, will also be investigated below.

\section{Observations}

In this paper, we make use of measurements within the postmidnight diffuse aurora made during the ARIA I campaign (Anderson et al., 1995; Larsen et al., 1995). The ARIA I campaign took place on 3 March 1992, and consisted of coor- dinated rocket, ground-based and satellite observations made at Poker Flat, Alaska (65.1 ${ }^{\circ} \mathrm{N}, 212.5^{\circ} \mathrm{E}$ geographic) during, and in the recovery phase of, a substorm which had an onset time of 10:00 UT. A rocket was launched during the campaign at 14:06 UT, making a trimethyl aluminate (TMA) release, which allowed the winds between 90 and 190-km altitude to be observed. Ion densities and electric fields were inferred from the measurements made throughout the campaign (see Brinkman et al., 1995). Four time intervals were defined, i.e. 10:00-11:30, 11:30-12:10, 12:10-13:20, and 13:20-14:10 UT, with different ion density and electric field structures for each interval (see Brinkman et al., 1995; Parish et al., 2003), and these values were used to provide auroral forcing inputs for the high resolution model. Zonal and meridional neutral winds measured during the ARIA I campaign are shown in Fig. 1 (see also Larsen et al., 1995, 1997).

\section{Model}

Simulations have been performed using a 3-D high resolution limited area, non hydrostatic, composition-dependent model, described in Parish et al. (2003). The location and extent of the computational domain in the simulations discussed in this paper consist of a region with vertical extent between $86 \mathrm{~km}$ and 451-km altitude, and horizontal dimensions $7140 \mathrm{~km}$ east-west and $3150 \mathrm{~km}$ north-south. The diffuse aurora has dimensions $3400 \mathrm{~km}$ east-west and $300 \mathrm{~km}$ north-south. The model domain is centered at $65 \mathrm{deg}$ magnetic latitude, and the cross auroral direction is taken to lie along a magnetic meridian. The ion drag forcing and Joule heating within the diffuse aurora drive the neutral winds, and these terms depend on the structures and magnitudes of the ion densities and electric fields, which are derived from the ARIA I measurements. The background ion density is based on the Chiu (1975) empirical model, which has been used for simplicity to specify the background ionosphere, rather than newer models, since the background ion density is small relative to the ion density enhancements which are being used in this investigation. The magnitude and structure of the ion density enhancement and electric field can be modified in the model. Large scale background winds in these simulations have been provided by the 3-D CTIP (Coupled Thermosphere Ionosphere Plasmasphere) lower resolution global model (Bailey et al., 1997; Fuller-Rowell et al., 1987). The CTIP model simulates the effects of different propagating diurnal and semidiurnal tides, assumed to propagate up from the troposphere and stratosphere into the thermosphere. Values of large scale winds from the CTIP model are rotated into magnetic coordinates and interpolated onto all the grid points of the high resolution model, to give background winds and tides in the auroral zone. 


\section{Sensitivity studies}

In order to determine the importance of auroral and tidal forcing in generating the strong neutral structure observed, the sensitivity of the neutral response to changes in auroral forcing and tidal forcing parameters has been investigated. The effects of changes in the amplitudes and phases of the different propagating tidal modes in the background winds, for given auroral electric fields and ion densities are discussed in Sect. 4.1. The effects of modifications in the time when the background winds are introduced, are investigated in Sect. 4.2. Section 4.3 examines the effects of changes in the orientation of the aurora relative to the background wind field. The effects of changing the auroral electric field and ion density magnitudes and structures for a given background wind field are described in Sect. 4.4. The relative importance of different forcing mechanisms is discussed in Sect. 5.

4.1 Varying tidal amplitudes and phases in the background winds

Our earlier study suggested that changes in the phase of the tides in the background wind field in the region of the postmidnight diffuse aurora may have significant effects on the neutral response (Parish et al., 2003). Propagating tides typically show significant day to day variability, but the effects of changes in the amplitudes and phases of the tides within the background wind field on the neutral response within the postmidnight diffuse aurora are not well known. The sensitivity of the neutral response to changes in the amplitude and phase of propagating tides in the CTIP background winds has been determined using model simulations, for constant auroral forcing parameters. The electric field and ion density structures are those inferred from measurements made during the ARIA I campaign, as described in Parish et al. (2003) and Brinkman et al. (1995), and simulations run from 10:00 to 14.10 UT for the day of the ARIA I campaign, 3 March 1992, corresponding to the period over which coordinated observations were made. Our previous results (Parish et al., 2003) suggest that higher order $(2,5)$ and $(2,6)$ semidiurnal propagating tidal modes are most important in generating vertical structure with features similar to those observed during the ARIA I campaign. Changes in the amplitudes and phases of the $(2,5)$ and $(2,6)$ tidal modes are therefore examined here.

\subsection{1 (2,5) tidal mode}

Figures $2 \mathrm{a}$ and $2 \mathrm{~b}$ show examples of the effects of changing the amplitude of the $(2,5)$ tidal mode within the background winds, whilst keeping the auroral forcing parameters constant, where the auroral forcing is based on the values observed during the ARIA I campaign, and where background winds are introduced at the start of the first interval. The direction of the background wind is given by the direction of the global winds and tides in the CTIP model, ro- tated into magnetic coordinates, for CTIP background conditions appropriate for the ARIA I measurements. The original ARIA observations are included in this figure for comparison (solid lines). The ranges of amplitudes for the $(2,5)$ mode were based on values found previously to produce reasonable agreement with the ARIA I wind observations (Parish et al., 2003), and to be consistent with values measured in recent satellite and ground based observations (e.g. Hecht et al., 1998; Karpov 1996; Dao et al., 1995). In this example, the amplitude of the geopotential height variation of the $(2,5)$ tidal mode in the background winds has been varied between $100 \mathrm{~m}$ and $300 \mathrm{~m}$, for a tidal phase of $3.0 \mathrm{~h} \mathrm{LT}$, where propagating tides are forced at the lower boundary of the CTIP model at $80-\mathrm{km}$ altitude. As the tidal amplitude is increased the magnitude peaks in the vertical structure stay at the approximately the same height, and the winds directions remain the same, but the magnitudes increase as the tidal amplitude is increased. The magnitude and strength of the shears is not as large as that found in the observations around 110 to $120 \mathrm{~km}$, especially in the case of the meridional wind.

Figures $2 \mathrm{c}$ and $\mathrm{d}$ show the effects of changing the phase of the $(2,5)$ tidal mode in the background winds, between 0.0 to $12.0 \mathrm{~h} \mathrm{LT}$, in increments of $3 \mathrm{~h}$, whilst keeping the same tidal geopotential amplitude constant at $300 \mathrm{~m}$, and with the same auroral forcing parameters, based on the ARIA I dawn side observations. The ARIA observations are not included in this and subsequent figures for clarity. Changing the phase has significant effects on the vertical structure. The heights of the wind maxima and their directions change as the phase of the tidal mode is varied, and the magnitude at a given height may also change, although the strength of the wind shears around 110 to $120 \mathrm{~km}$ is still smaller than that observed.

\subsection{2 (2,6) tidal mode}

Figures $3 \mathrm{a}$ and $\mathrm{b}$ show the effects of including the $(2,6)$ semidiurnal tidal mode in the background winds, instead of the $(2,5)$ mode. In Figs. $3 a$ and 3 the geopotential amplitude has been varied between 100 and $300 \mathrm{~m}$, for phase $5.0 \mathrm{~h} \mathrm{LT}$, keeping the same ARIA I auroral forcing parameters. The peak magnitudes increase with increasing tidal amplitude, as was seen for the $(2,5)$ mode. The wind peaks in each direction occur at slightly lower altitudes for the $(2,6)$ mode than for the $(2,5)$ mode, most likely due to the shorter vertical wavelength of the $(2,6)$ mode (Chapman and Lindzen, 1970). The heights of the wind magnitude peaks and the wind directions vary significantly with the tidal phase (Figs. $3 \mathrm{c}$ and $3 \mathrm{~d})$. The magnitude peaks below around $130 \mathrm{~km}$ tend to be stronger and occur at slightly lower altitudes for the $(2,6)$ mode compared with the $(2,5)$ mode, consistent with the shorter vertical wavelength of the $(2,6)$ mode. 
a.

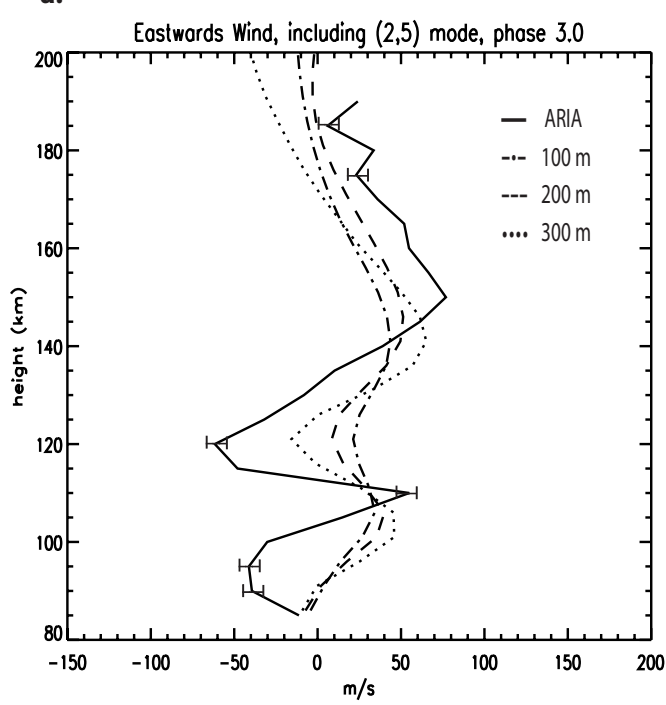

$$
\text { c. }
$$

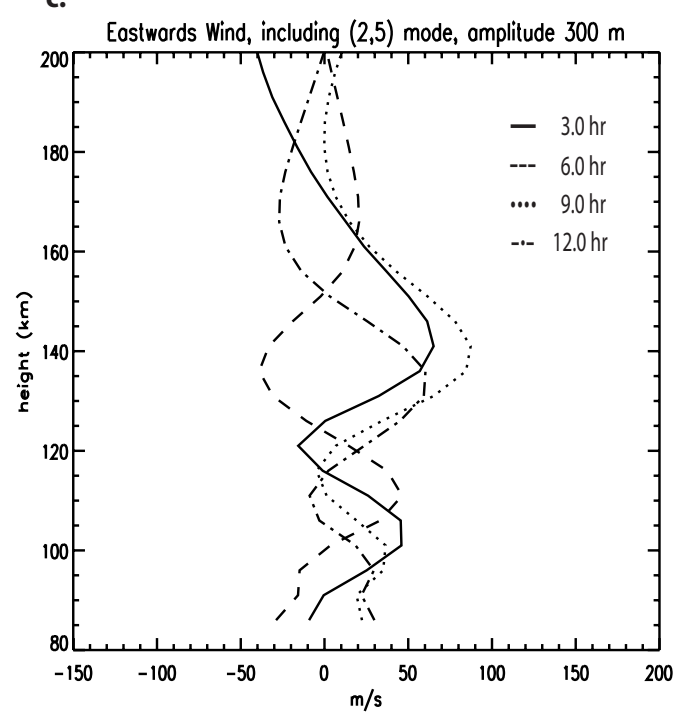

b.

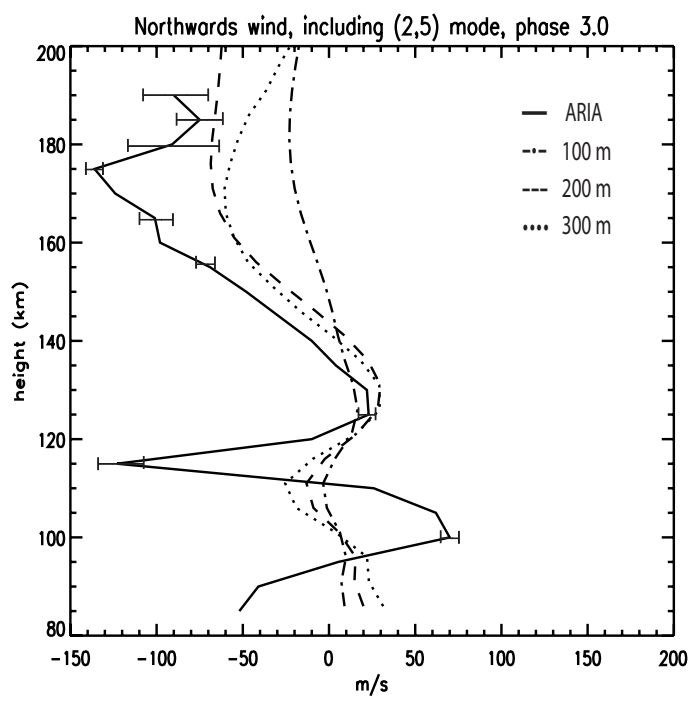

d.

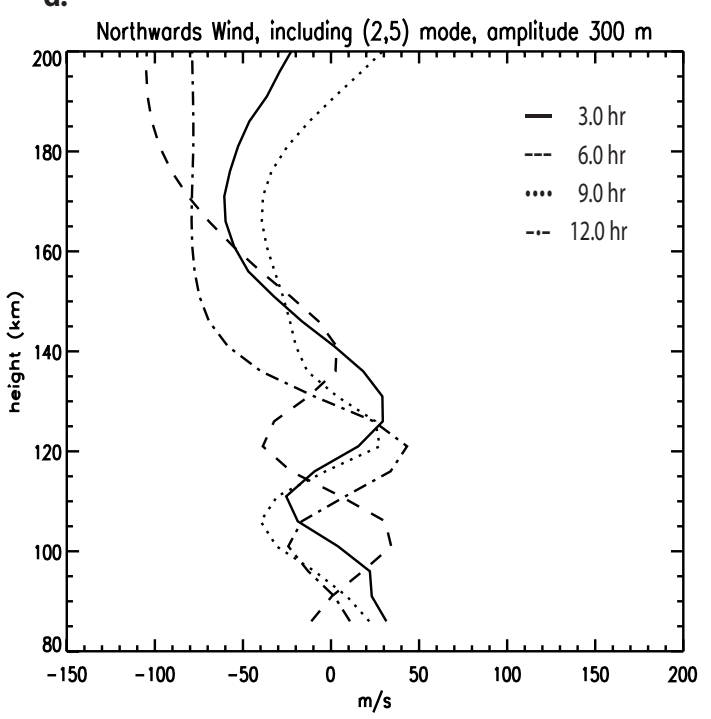

Fig. 2. (a), (b) Response of the neutral winds to changes in the (2,5) mode tidal amplitude in the background winds compared with ARIA I observations, and (c), (d) response of the neutral wind to changes in $(2,5)$ mode tidal phase in the background winds.

4.2 Effects of modifying the time when background winds are introduced

Background winds and tides appear to have important effects on the wind structures, and tides are also known to vary significantly (e.g. Pancheva et al. 2000; Beard et al., 1999; Canziani, 1994; Phillips and Briggs, 1991). Experiments were performed to determine the effects of introducing background winds and tides at different times relative to the time at which the auroral forcing is introduced, to investigate the effects of changes in the background winds in the presence of auroral forcing. As discussed above, four time intervals were defined for the ARIA I measurements (Brinkman et al., 1995; Parish et al., 2003), with different ion density and electric field structures for each interval. For the simulations described here, the background winds and tides were not introduced until the start of a specified interval, whilst auroral forcing was applied throughout the four time intervals. Though not intended to be entirely physically realistic, these experiments do demonstrate the importance of the background wind field in the development of the response to the auroral forcing. The effects of introducing background winds at the beginning of each of the four different time intervals respectively, are shown in Figs. 4a and b. Background winds in this example included the $(2,5)$ tidal mode, with amplitude $300 \mathrm{~m}$, phase $3.0 \mathrm{~h}$. The results displayed in Figs. $4 \mathrm{a}$ and $\mathrm{b}$ show that the neutral wind is noticeably affected by the timing of the introduction of background winds, 
a.

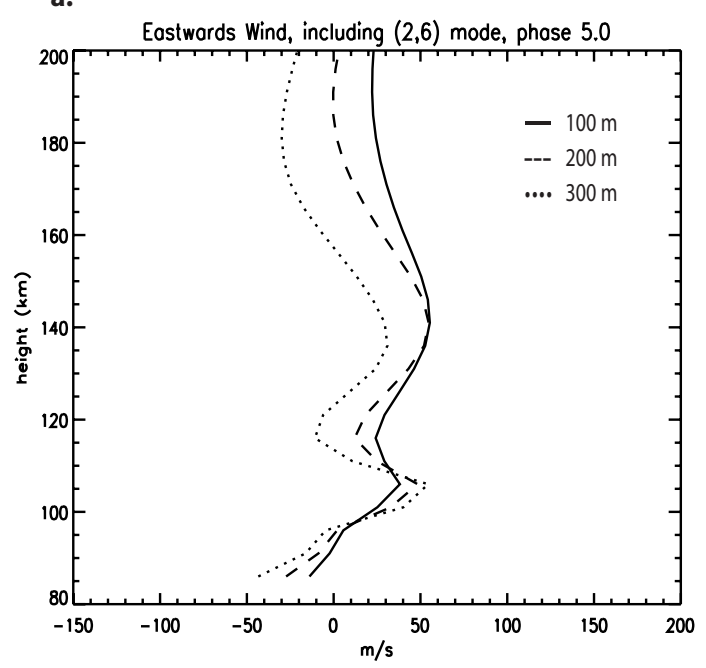

c.

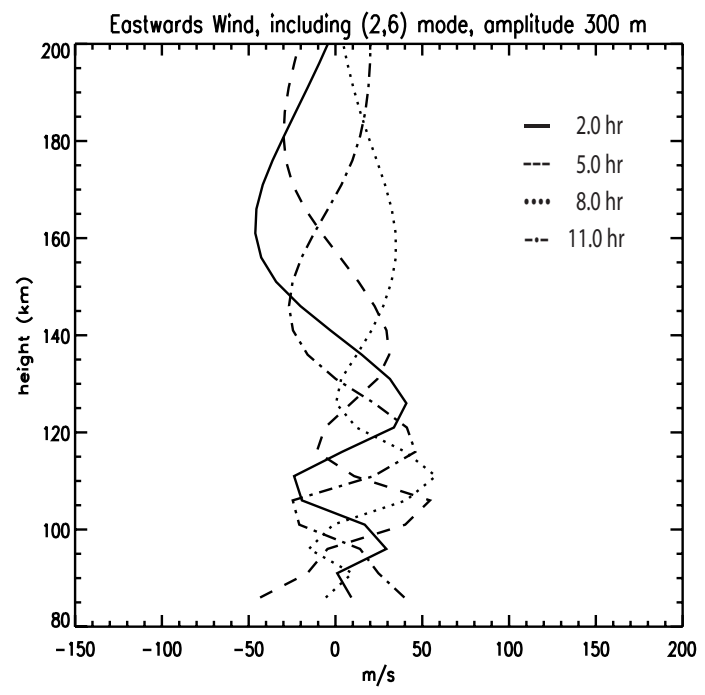

b.

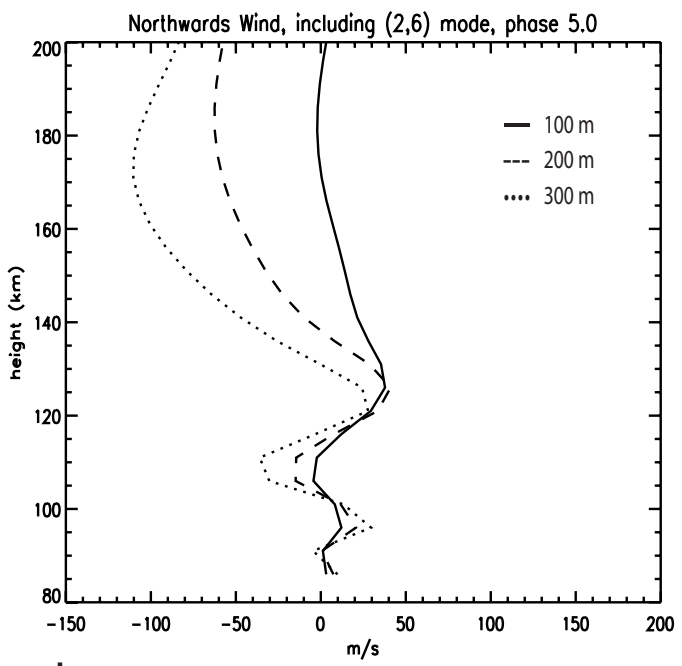

d.

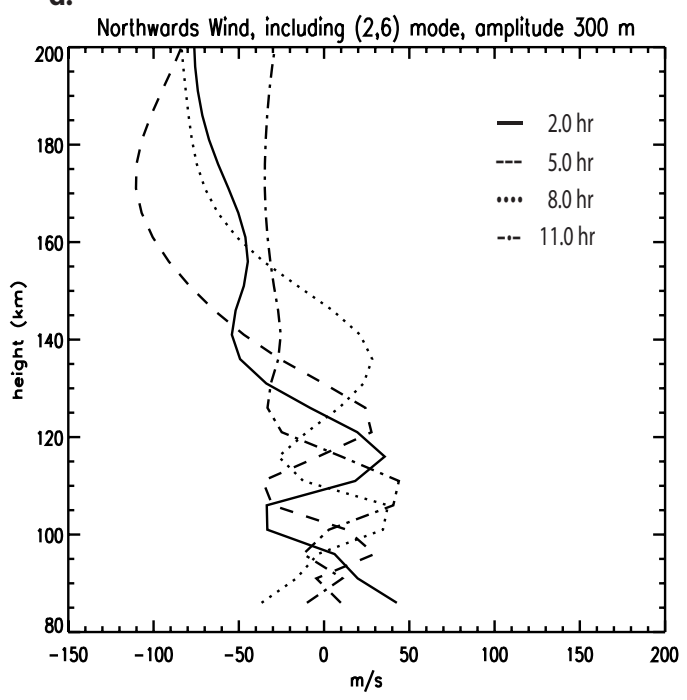

Fig. 3. (a), (b) Response of the neutral winds to changes in the $(2,6)$ mode tidal amplitude in the background winds, and (c), (d) response of the neutral wind to changes in $(2,6)$ mode tidal phase in the background winds.

especially above around $120-\mathrm{km}$ altitude. The general shape of the vertical wind structure remains the same, but the magnitude of the wind at a given height, as well as the altitude of the peak, varies. Wind changes are seen in the $\mathrm{E}$ region of around 10 to $20 \mathrm{~m} / \mathrm{s}$ up to $120-\mathrm{km}$ altitude, for wind magnitudes in the range of 10 to $40 \mathrm{~m} / \mathrm{s}$, and changes of up to $50 \mathrm{~m} / \mathrm{s}$ in the zonal wind and $20 \mathrm{~m} / \mathrm{s}$ in the meridional wind are seen around 130-km altitude. Previous studies (Walterscheid and Lyons, 1989; Fuller-Rowell, 1985) suggest that background cross auroral winds tend to reduce the acceleration of the winds within the auroral arc, and the results shown here suggest that the longer the time that strong background winds, which have a cross arc component, are present, the weaker is the acceleration of the resulting wind structure due to auroral forcing. This suggests that the time history of the background winds as well as the strength of the aurora forc- ing can be important in shaping the neutral wind response in the region of the diffuse aurora.

\subsection{Changes in orientation of background winds}

Simulations were performed to determine the sensitivity of the neutral response to changes in the orientation of the background winds relative to the aurora. As discussed above, many satellite and ground based investigations suggest that the strength and structure of the large scale convection at high latitudes is strongly influenced by the orientation of the solar wind IMF, and changes in the IMF may therefore affect the direction of the aurora relative to the background wind field, which in turn may affect whether background winds are directed along or across the auroral arc. Previous studies suggest that the magnitude of the neutral winds accelerated 
a.

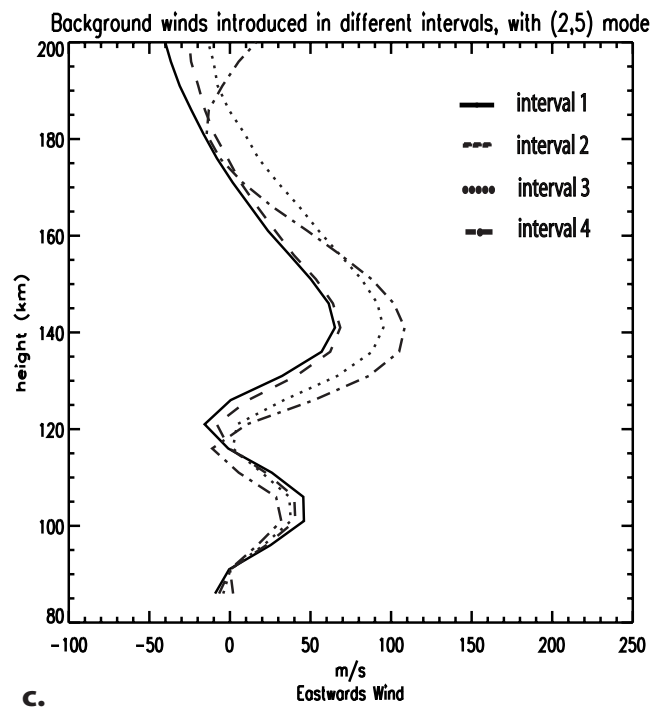

c.

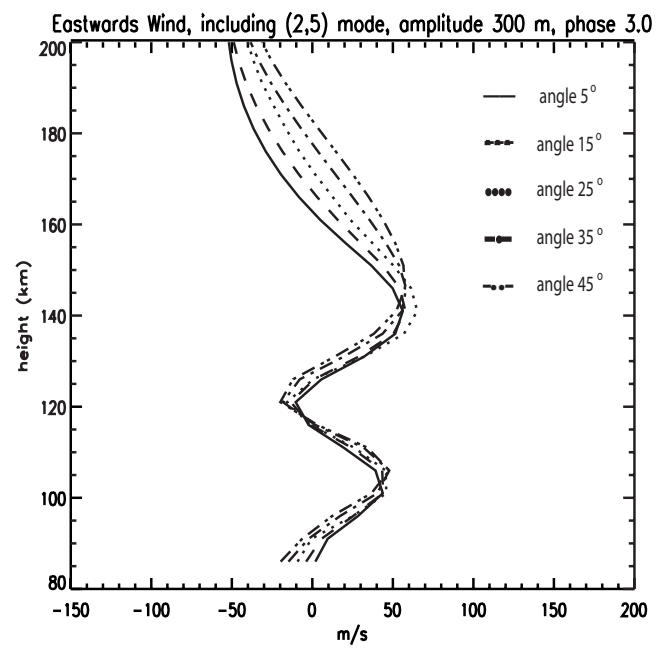

b.

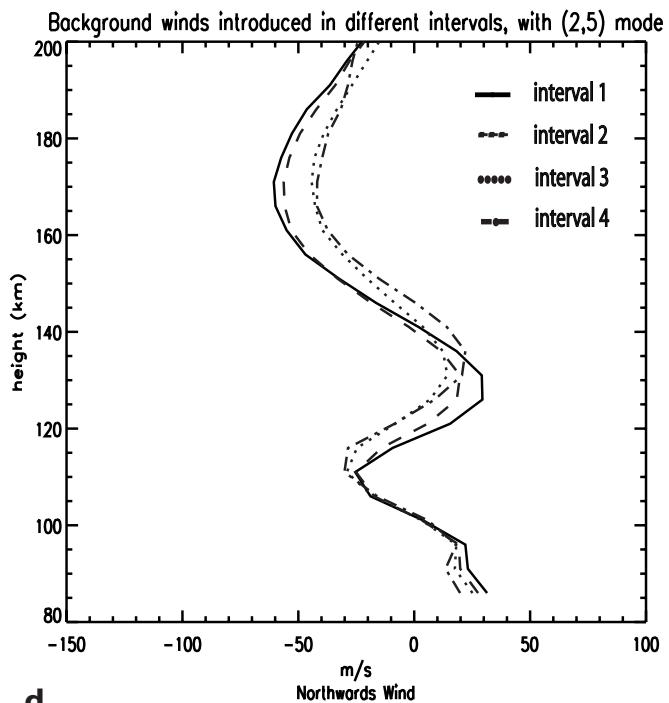

d.

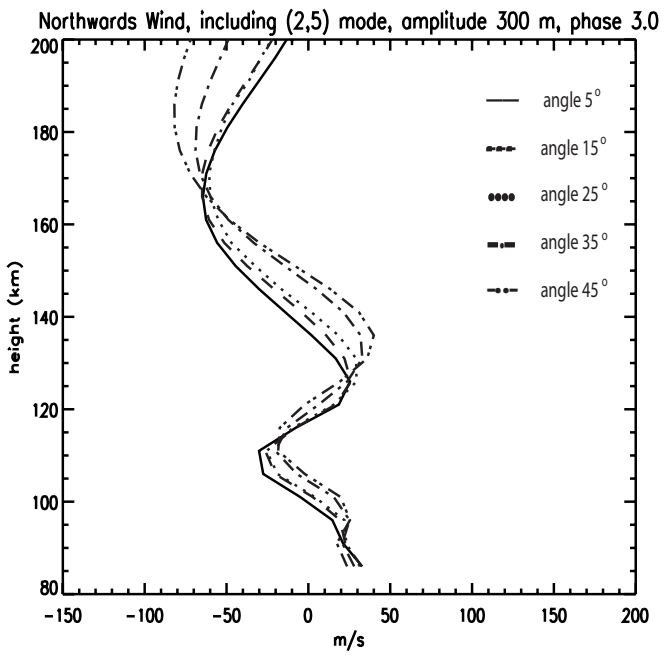

Fig. 4. (a), (b) Effects of introducing background winds including the (2,5) mode at the beginning of different intervals, and (c), (d) effects of changing the angle between the aurora and the background wind field.

by auroral forcing can be influenced by whether background winds are oriented along or across the auroral arc (Walterscheid and Lyons, 1989; Fuller-Rowell, 1985).

Figures $4 \mathrm{c}$ and $\mathrm{d}$ show the effects of varying the angle between the diffuse aurora and the background wind field. Results are shown for a range of values of eastwards angle between $5 \mathrm{deg}$ and $45 \mathrm{deg}$, where the range of values are perturbations of 10 to $20 \mathrm{deg}$ around an angle of $25 \mathrm{deg}$ which approximates the angle between the diffuse aurora and the background wind field for the ARIA I observations, based on the angle between geographic and magnetic coordinates at Poker Flat during the ARIA I campaign (given by e.g. NOAA Geophysical Data Center). The chosen range of variations in the orientation of the diffuse aurora for the dawn sector is estimated from statistical studies of the effects of changes in
IMF angle on the electric potential structure (Weimer, 2001, 1996, 1995). Electric field and ion density structures are from the ARIA I measurements, and background winds including the $(2,5)$ mode, with geopotential amplitude $300 \mathrm{~m}$ and phase $3.0 \mathrm{~h} \mathrm{LT}$ were introduced during the first interval. As the angle is modified the direction of the wind maxima remains the same, but the height of the peaks are progressively changed for both the eastwards and northwards wind directions, and the magnitudes at the wind maxima may also increase or decrease. This suggests that IMF related changes in orientation which are of reasonable magnitude with respect to observations, can have noticeable effects on the neutral wind structure, although the changes are smaller than the effects of changes in tidal amplitudes and phases at $\mathrm{E}$ region altitudes. A change of $20 \mathrm{deg}$ in orientation of the 
a.

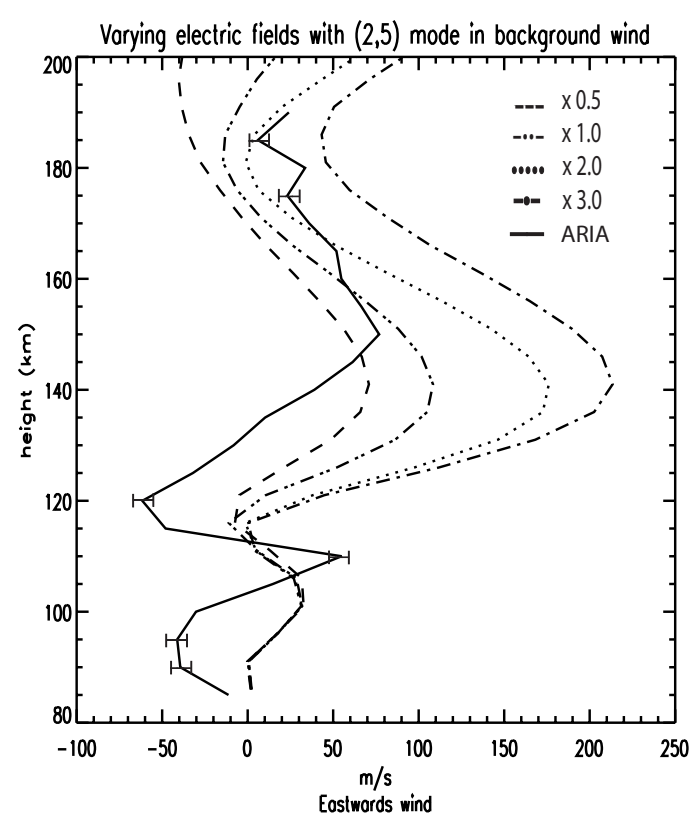

c.

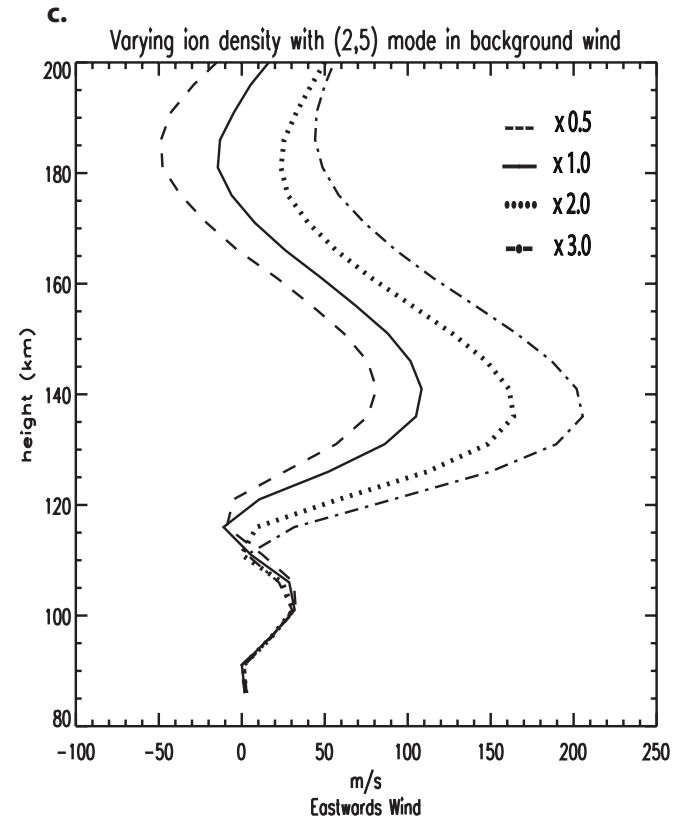

b.

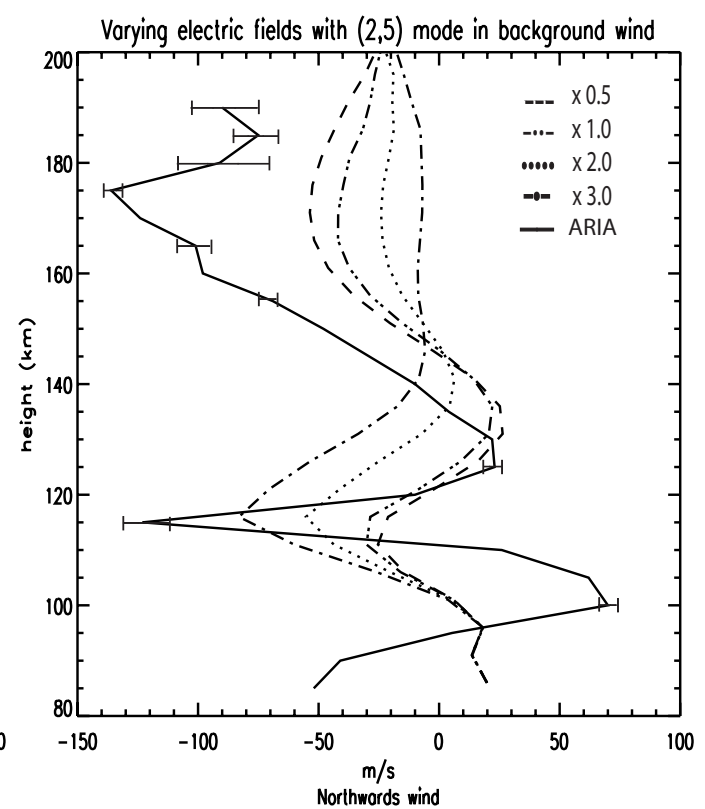

d.

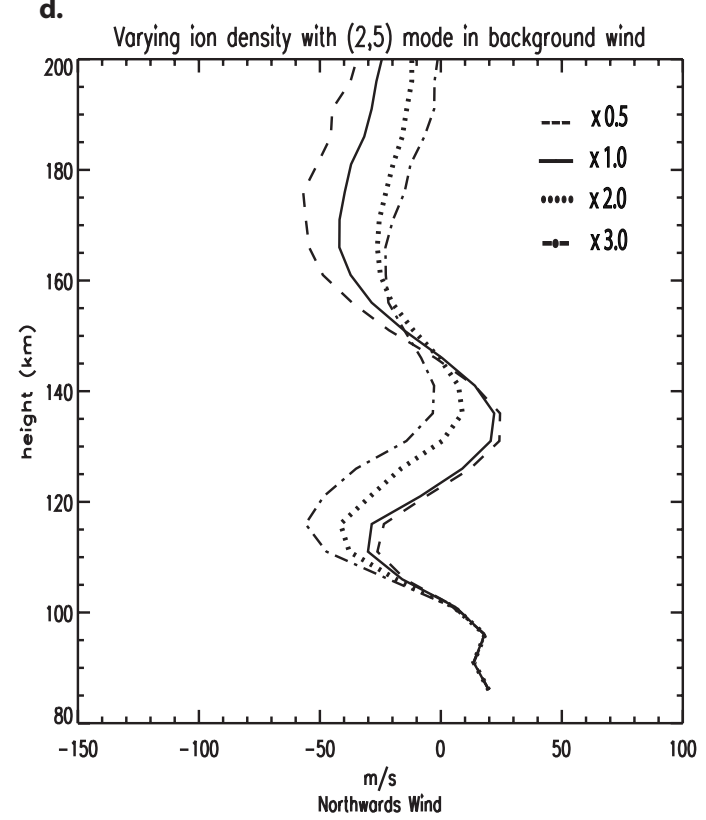

Fig. 5. (a), (b) Response of the neutral winds to varying electric field magnitude, with $(2,5)$ tidal mode in the background winds. The ARIA I observations are included for comparison. $(\mathbf{c}),(\mathbf{d})$ Response of neutral wind to varying ion density enhancement, with $(2,5)$ tidal mode in the background winds.

aurora relative to the background wind field may produce up to around a $20 \%$ change in the peak neutral wind magnitudes in the $\mathrm{E}$ region.

\subsection{Variation of auroral forcing parameters}

Studies were also performed to determine the sensitivity of the neutral response to changes in auroral forcing parameters.

\subsubsection{Electric field variations}

The effects of modifying the electric field magnitude measured during the ARIA I campaign, whilst the original ion density, from the same campaign, is kept the same, are shown in Figs. 5a and 5b. The electric field and ion density structures for the different intervals were as specified in Brinkman et al. (1995). The maximum electric field varied 
a.

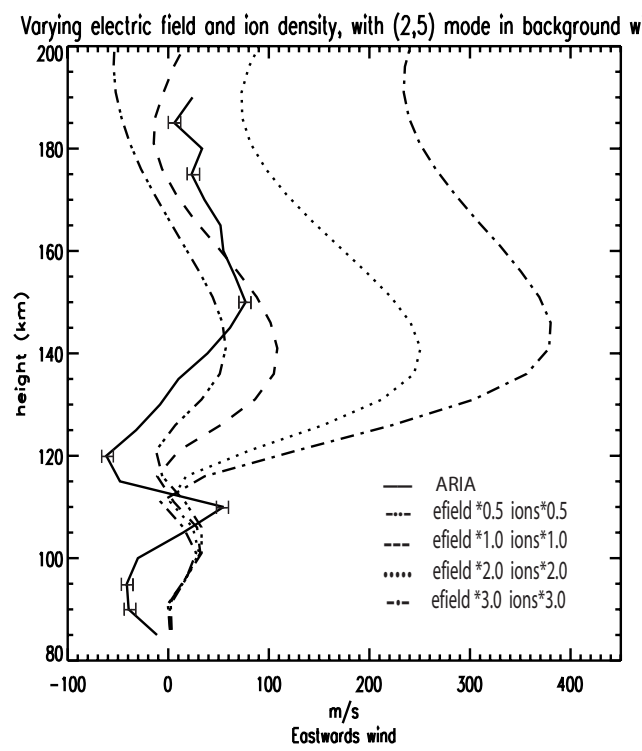

b.

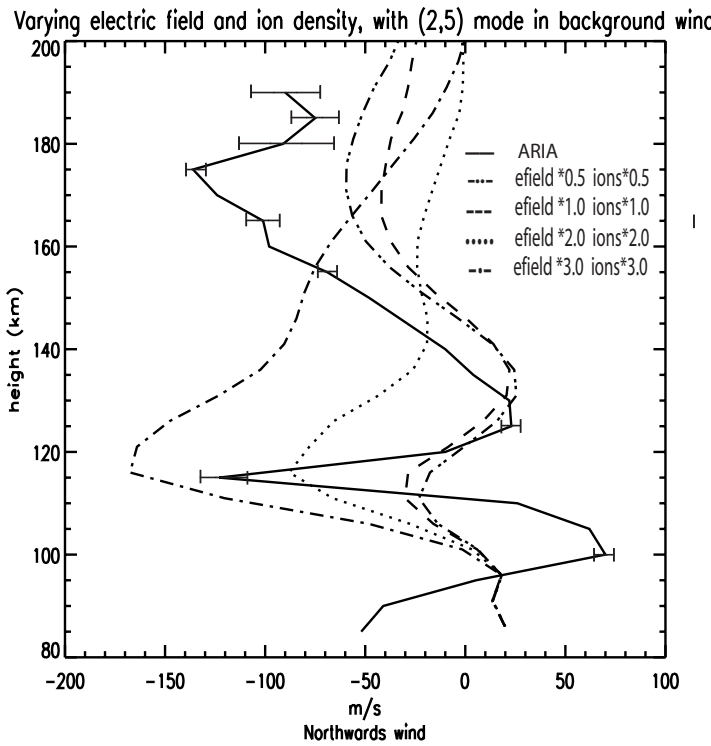

Fig. 6. (a), (b) Response of the neutral winds to varying electric field and ion density enhancement, with $(2,5)$ tidal mode in the background winds. The ARIA I observations are included for comparison.

between around $3 \mathrm{mV} / \mathrm{m}$ at $66 \mathrm{deg}$ latitude during the first interval, to around $34 \mathrm{mV} / \mathrm{m}$ at $68 \mathrm{deg}$ latitude, in the fourth interval. The maximum ion densities varied from around $1.5 \times 10^{11} \mathrm{~m}^{-3}$ at $120-\mathrm{km}$ altitude during the first interval to around $4.0 \times 10^{11} \mathrm{~m}^{-3}$ at $110-\mathrm{km}$ altitude during the fourth interval. Background winds include the $(2,5)$ tidal mode, with amplitude $300 \mathrm{~m}$ and phase $3.0 \mathrm{~h}$. In these examples, background winds have been introduced at the start of the fourth interval. In this figure, the original ARIA observations (solid lines) are included for comparison. The electric field has been multiplied by factors between 0.5 and 3.0 relative to the original values estimated from the ARIA I measurements. As the electric field is increased the eastwards wind increases above $120 \mathrm{~km}$, and the peak around $140 \mathrm{~km}$ increases significantly, becoming much larger than that observed, but the magnitude of the westwards peak around $115 \mathrm{~km}$ is slightly reduced, and is still much smaller than observed. The southwards wind peak increases around $120 \mathrm{~km}$ as the electric field is increased, but the peaks in the structure above that altitude are reduced in magnitude. The magnitude of the southwards peak around $115 \mathrm{~km}$ is significantly increased, but is still smaller than the observed peak, and the shears above and below the peak are not as strong as those observed.

\subsubsection{Ion density variations}

Figures $5 \mathrm{c}$ and $\mathrm{d}$ show examples of the effects of changing the magnitude of the original ARIA I ion density enhancement, whilst the electric field from the same campaign and the background ion density estimated from the Chiu (1975) model are kept the same. Background winds include the $(2,5)$ tidal mode, with constant amplitude $300 \mathrm{~m}$ and phase $3.0 \mathrm{~h}$, introduced at the start of interval four. As the ion density enhancement is increased from 0.5 to 3.0 times the original ARIA I values, the eastwards wind increases significantly above around $120 \mathrm{~km}$. The southwards wind peak increases around $120 \mathrm{~km}$, but the magnitudes of the peaks in the structure decrease above that altitude. The increase in the southwards wind around $120 \mathrm{~km}$ is larger for an increase in the electric field than for a corresponding increase in the ion density (Figs. 5b and d). Changes in the electric field and ion density have only small effects below around $110 \mathrm{~km}$, where the structure appears to be mainly influenced by the tidal variations.

\subsubsection{Electric field and ion density modified together}

Figure 6 shows the effects of modifying the magnitude of the electric field and ion density enhancement at the same time, as might occur for example within a very strong diffuse aurora with strong electric fields. The ARIA observations are included in the figure for comparison. The electric field and ion density enhancement are both multiplied by $0.5,1.0$, 2.0 or 3.0 respectively, with background winds including the $(2,5)$ mode, with amplitude $300 \mathrm{~m}$, and phase $3.0 \mathrm{~h}$, introduced in interval four. As the electric field and ion density enhancement are increased together, the height of the westwards peak around $120 \mathrm{~km}$ decreases slightly in magnitude and altitude, and the eastwards peak around $140 \mathrm{~km}$ remains at approximately the same height, but increases considerably 
a.

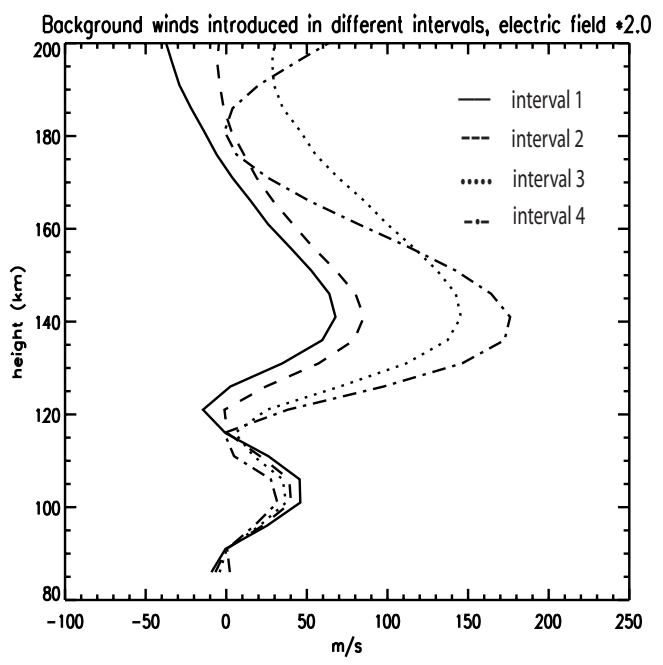

c.

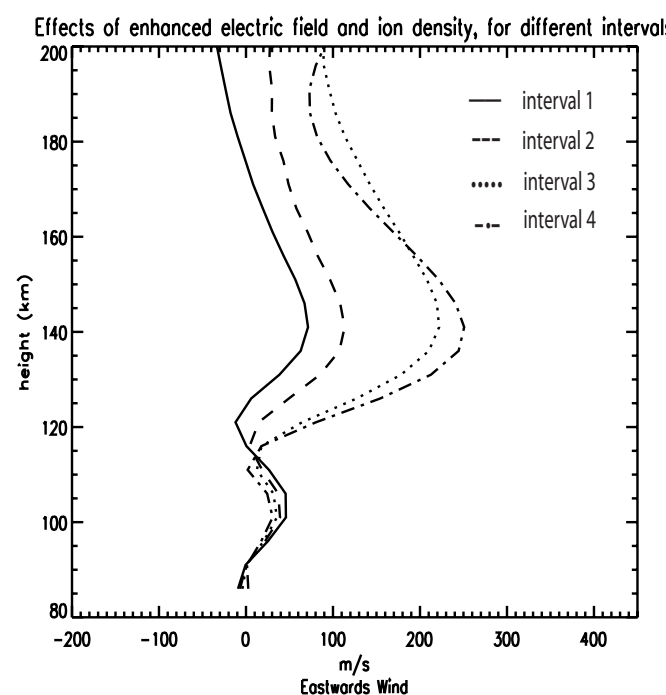

b.

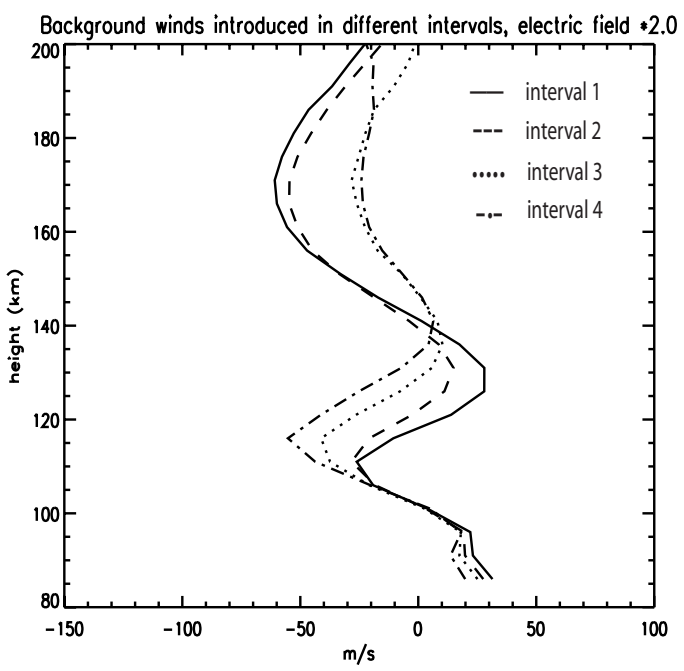

d.

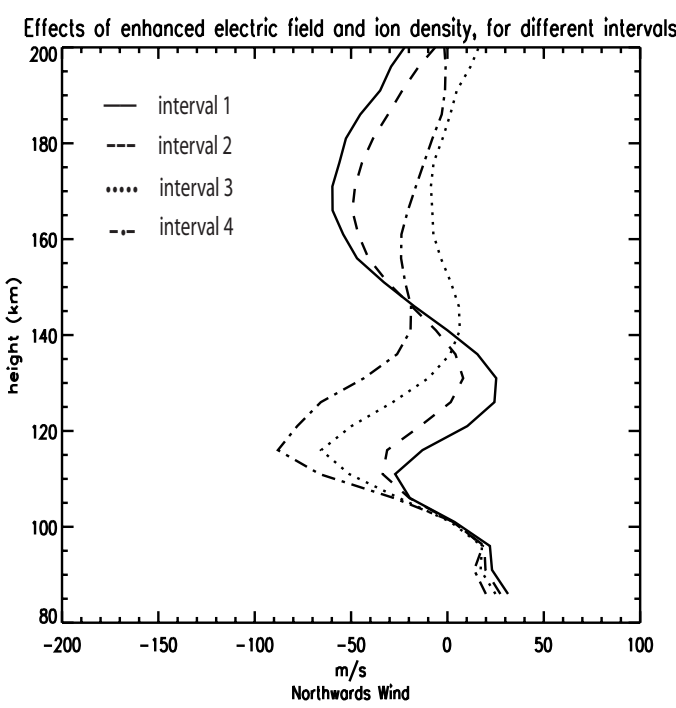

Fig. 7. (a), (b) Effects of multiplying the electric field magnitude by 2.0 for background winds introduced at the beginning of different intervals. (c), (d) Effects of multiplying both the electric field and ion density enhancement by 2.0, for background winds introduced at the beginning of different intervals.

in magnitude relative to the values produced when either the electric field or ion density enhancement are increased separately. The southwards wind peak around 115 to $120 \mathrm{~km}$ increases in height and is enhanced substantially in magnitude when the electric field and ion density enhancement are increased together, whilst the northwards peak around $140 \mathrm{~km}$ is reduced in magnitude, or reverses direction and merges with the southwards peak around $120 \mathrm{~km}$. Increasing the electric field and ion density enhancement together produces an eastwards peak around $140-\mathrm{km}$ altitude which is larger than that observed, and tends to reduce the magnitude of the westwards peak around 110 to $120 \mathrm{~km}$. The magnitude of the southwards peak around $115 \mathrm{~km}$ is increased to magnitudes similar to those observed, but the peak is much broader in altitude than in the observations, and the observed northwards peak around $130 \mathrm{~km}$ disappears.

As discussed above, the effects of varying the electric field and ion density depend on the time when the background winds and tides are introduced. Figures $7 \mathrm{a}$ and $\mathrm{b}$ show the response when the electric field is doubled, for background winds introduced in intervals 1 through 4 , respectively. The response when the electric field and the ion density enhancement are both doubled, is shown in Figs. 7c and d, for background winds introduced in intervals 1 through 4 . The results in Fig. 7 show that the effects of enhanced auroral forcing are greater when the background winds are introduced in later 
a.

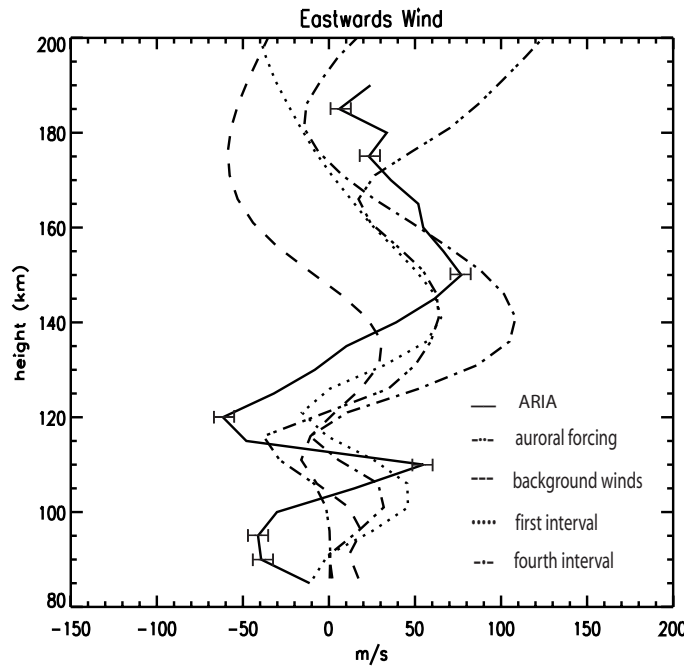

c.

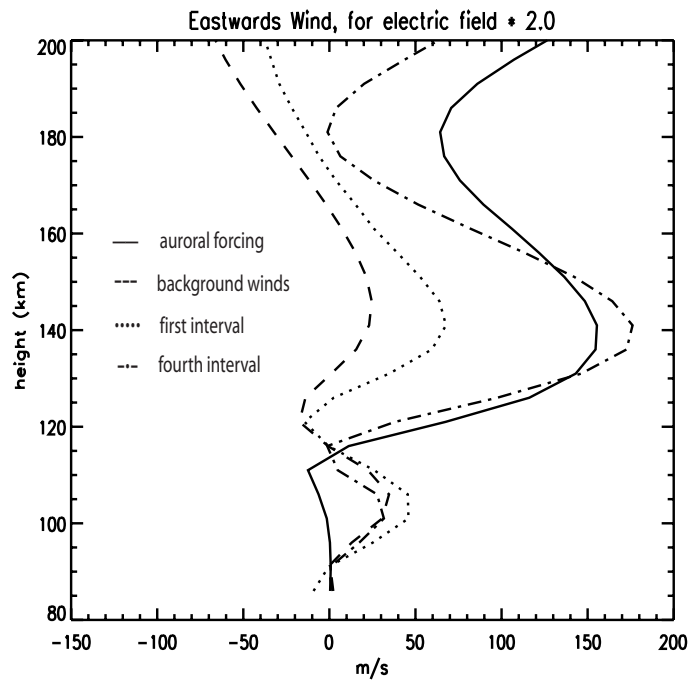

b.

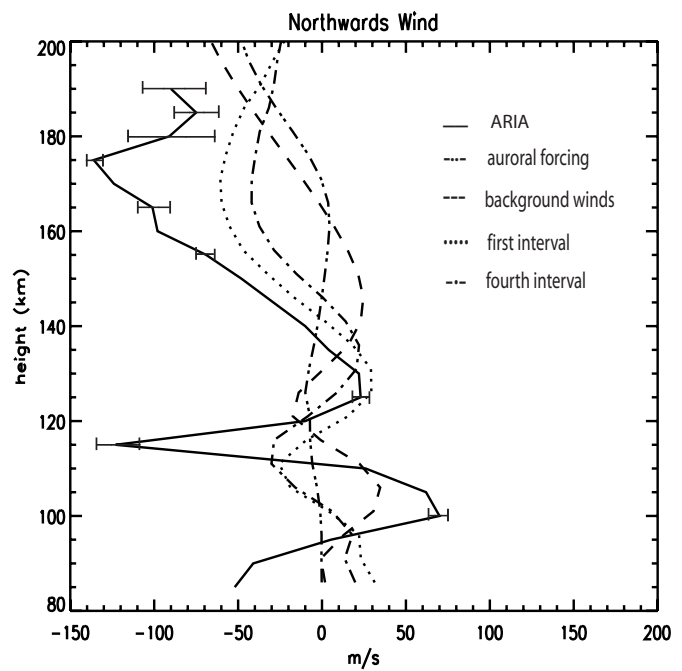

d.

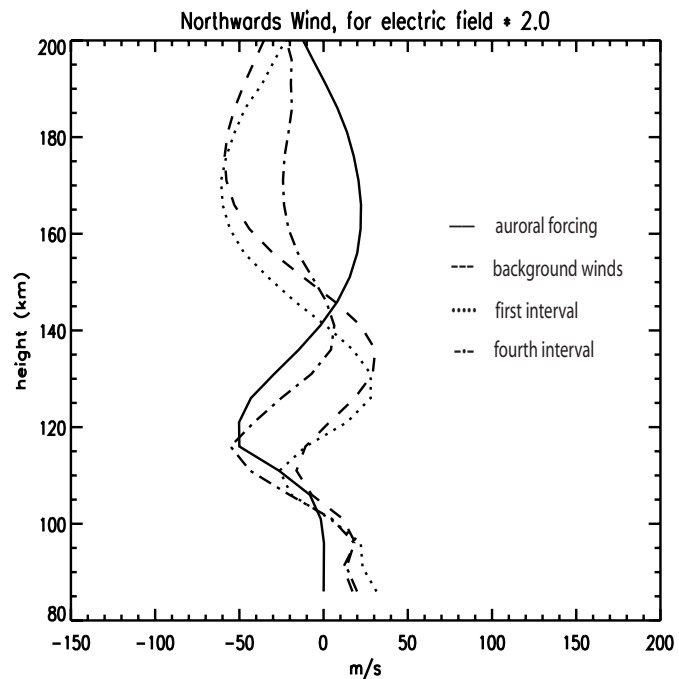

Fig. 8. (a), (b) Response of the neutral winds to different combinations of auroral forcing and background winds and tides, with ARIA I observations included for comparison. (c), (d) Response of the neutral winds to different combinations of auroral forcing and background winds and tides, with the electric field multiplied by 2.0 .

intervals, when the thermosphere has had more time to respond to the auroral forcing. The effects of changes in auroral forcing parameters, as shown in Figs. 5 and 6, are therefore less pronounced for cases in which background winds are introduced earlier.

\section{Relative importance of different forcing mechanisms}

Figures $8 \mathrm{a}$ and $8 \mathrm{~b}$ show the response of the eastwards and northwards winds to different combinations of auroral forcing and background winds and tides. The dash-double-dot lines show the effects of auroral forcing only based on the ARIA I observations, with no background winds. The dashed line shows the background winds only, including $(2,5)$ mode, with amplitude $300 \mathrm{~m}$ and phase $3.0 \mathrm{~h}$ LT. The response when background winds including the same $(2,5)$ mode, are introduced at the start of the first interval, are shown with the dotted line. The response when background winds including the $(2,5)$ mode are introduced at the start of the fourth interval, are shown by the dash-dot line. The ARIA observations are shown for comparison (solid line). The results of the simulations suggest that most of structure below about $110 \mathrm{~km}$ is related to background winds and tides. When electric field and ion densities inferred from ARIA observations are applied alone, without background winds, there is very little structure in the meridional wind in particular. When background 
a.

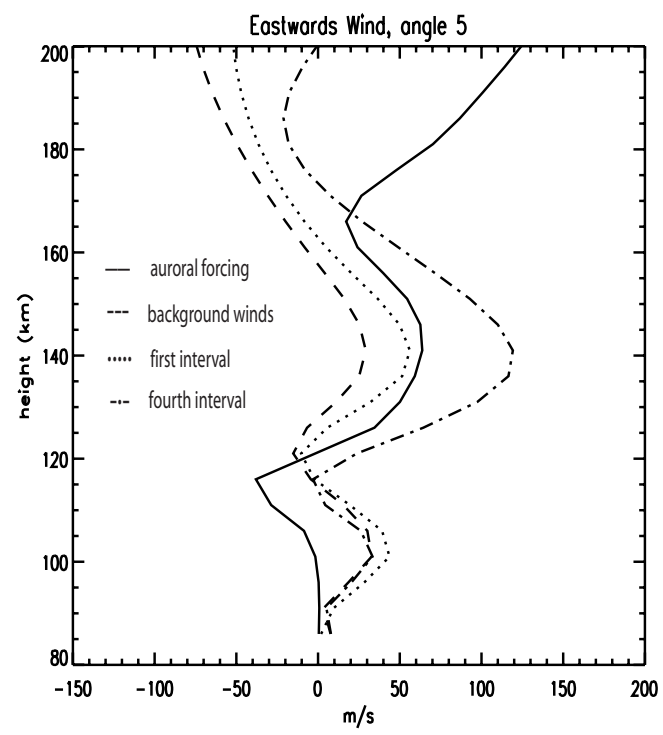

c.

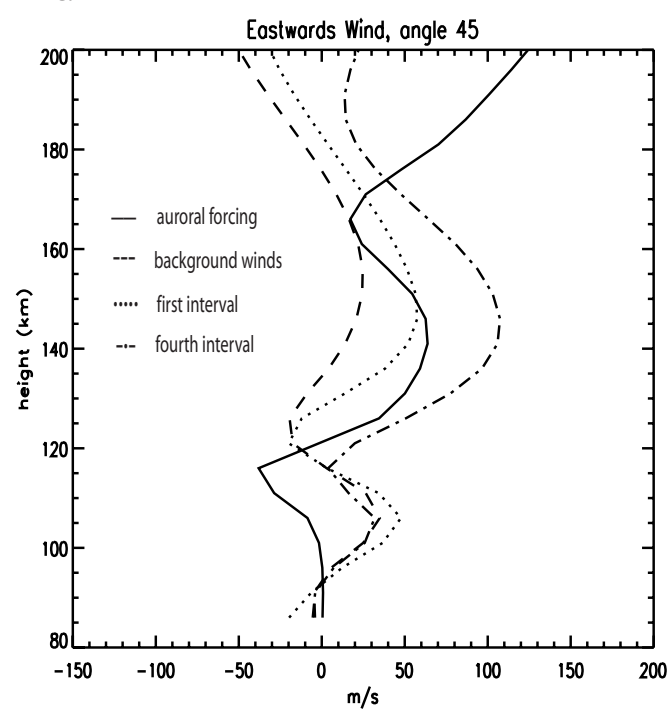

b.

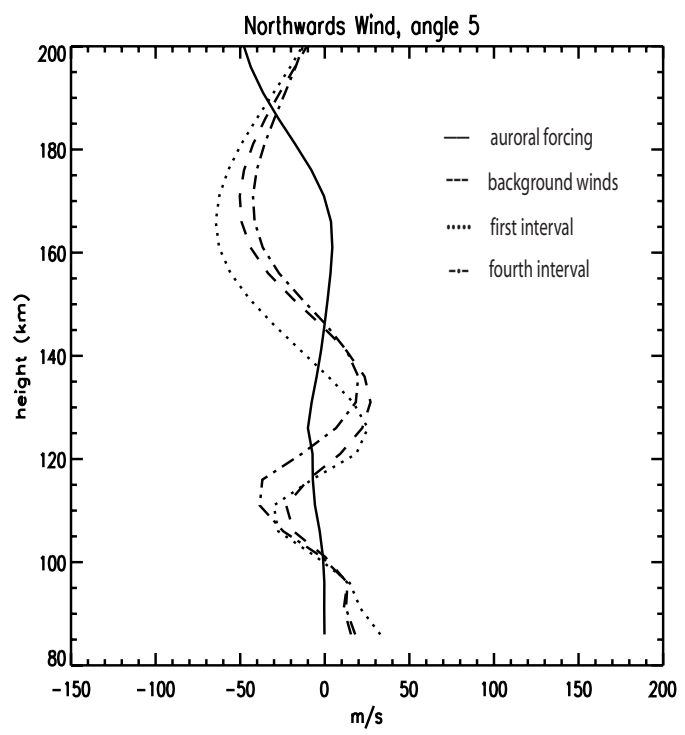

d.

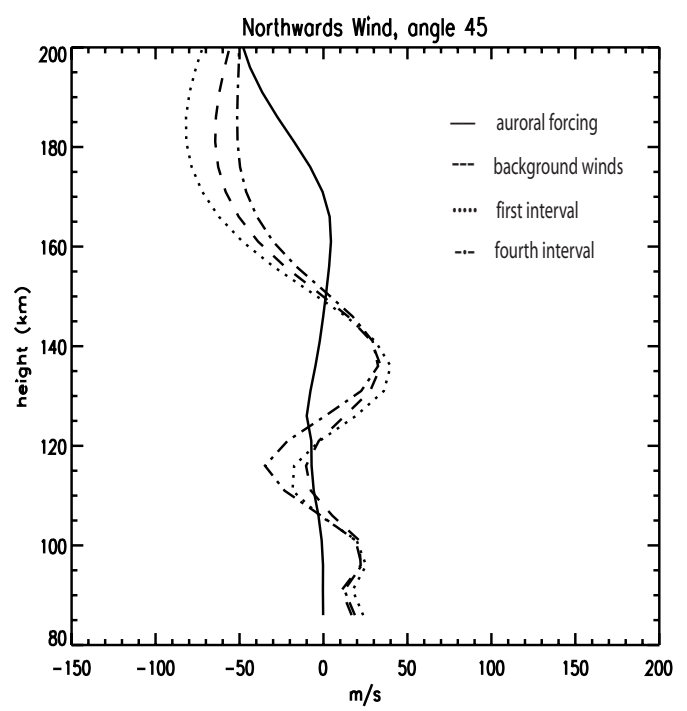

Fig. 9. Response of the neutral winds to different combinations of auroral forcing and background winds and tides, for different angles between the background wind field and the auroral direction (a), (b) $5 \mathrm{deg}$, (c), (d) $45 \mathrm{deg}$.

winds are introduced in the first interval, the structure above $110 \mathrm{~km}$ tends to be more affected by tidal variations, for example in terms of the height of the westwards peak around $120 \mathrm{~km}$, and the magnitude of the eastwards peak around $140 \mathrm{~km}$. When background winds are applied later, the structure above $110 \mathrm{~km}$ tends to be more strongly influenced by auroral forcing processes.

Figures $8 \mathrm{c}$ and $\mathrm{d}$ show the corresponding response of the eastwards and northwards winds for different combinations of auroral forcing and tidal forcing. The electric field inferred from the ARIA I measurements has been doubled, whilst maintaining the original ion density. The same $(2,5)$ tidal mode has been included in the background winds. The results show that most of structure below about $110 \mathrm{~km}$ still appears to be due to background winds and tides. When auroral forcing is applied alone, and the electric field inferred from the ARIA observations is doubled, more structure is seen in the meridional wind than for the original electric field. When the background winds are introduced in the first interval, the profile above $110 \mathrm{~km}$ appears to be more influenced by the background wind structure, and when background winds are introduced in the fourth interval, the structure shows more influence from auroral forcing processes. However, the wind profiles both above and below $110 \mathrm{~km}$ 
show more similarities in structure to those observed during the ARIA I campaign when some tidal variations are present in the background winds, and auroral forcing alone does not produce good agreement with the observations.

If the angle of the background winds is changed relative to the auroral direction, the wind structure is modified as the angle changes, as discussed above, but the relative importance of auroral or tidal processes in generating the wind structure tends to show the same dependence on the time when the background winds are introduced, with auroral forcing affecting the structure more strongly when background winds are introduced later. For example, Figs. $9 \mathrm{a}$ to $\mathrm{b}$ and $\mathrm{c}$ to $\mathrm{d}$ show a comparison of the response of the winds to different forcing processes for angles of $5 \mathrm{deg}$ and $45 \mathrm{deg}$, respectively. The response shows more similarities to the background wind profile when the background winds are introduced in the first interval, in terms of the heights and magnitudes of the wind peaks, and shows more similarities to the effects of auroral forcing alone when background winds are introduced in the fourth interval.

\section{Discussion}

Changes in input parameters for the tidal and auroral forcing can have significant effects on the neutral wind structure, and peak magnitudes similar to those observed can be produced for reasonable values of auroral and tidal forcing parameters. However, the strength of the observed shears, especially the shear between around 110 and $120-\mathrm{km}$ altitude, is not well reproduced. One possible explanation may be the presence of vertical structure within the tides in the background winds, which is on smaller vertical scales than can be resolved with the CTIP model used to generate the background winds for these simulations (one scale height resolution). There may also be waves which are not currently included in the simulations, for example gravity waves. Gravity waves can propagate up into the lower thermosphere, and may be dissipated there. They tend to have smaller vertical wavelengths than tides, and are currently not included in the CTIP or high resolution models. Non-migrating semidiurnal tides may also be important at high latitudes (Portnyagin et al., 1998; Forbes et al., 1995), and are not currently included in the CTIP model. Nonlinear interactions between different kinds of waves, for example between different tidal modes, gravity wave and tides, or gravity waves and planetary waves, may also generate secondary waves with different characteristics from the original variations (e.g. Pancheva et al., 2004; Isler and Fritts, 1996; Forbes and Miyahara, 1991).

In this investigation, higher order semidiurnal propagating tidal modes, which have relatively small vertical wavelengths, were included in the background winds. The propagating diurnal $(1,1)$ tide also has a relatively short vertical wavelength, and does propagate up into the lower thermosphere, where it is soon dissipated. The short vertical wave- length of the $(1,1)$ mode suggests the possibility that this tidal mode could be associated with short scale size vertical variations. However, when the $(1,1)$ mode was included in the CTIP background winds, there were only minor effects on the neutral structure. This is consistent with the fact that the propagating $(1,1)$ mode has a relatively low amplitude at high latitudes, with a peak amplitude around 20 to 30 deg latitude, and the $(1,1)$ mode is also strongly dissipated above around 105-km altitude (e.g. Zhang and Shepherd, 2005).

\section{Conclusions}

When background winds including propagating tides are introduced into simulations of the postmidnight diffuse aurora with amplitudes based on observations, in addition to electric field and ion density structures estimated from measurements, the simulated neutral wind profiles display many of the features of those observed (Parish et al., 2003), although the strength of the simulated wind shears is not as large as those observed. Changes in the auroral forcing parameters, the amplitudes and phases of the tidal variations, and the orientation of the IMF, are all found to affect the neutral response. When propagating tides are included as well as the auroral forcing, tidal variations appear to produce most of the neutral wind structure below around $110 \mathrm{~km}$. Changes in the tidal amplitudes, within a reasonable range of values based on observations, as well as changes in tidal phase, which can be variable from day to day, may both have significant effects on the neutral structure. Increasing the magnitude of tidal variations changes the magnitudes of peaks in the neutral structure at all altitudes. Changing the phase of the tidal variations modifies the magnitudes and heights of the peaks in the neutral wind structure at all altitudes. When the auroral orientation relative to the background wind field is modified, for a small range of angles which might be caused by changes in the interplanetary magnetic field for example, the magnitude peaks in the wind profile maintain the same direction, but change slightly in altitude, and the magnitudes at the peaks are changed. When the magnitude of the electric field, or the magnitude of the ion density enhancement is increased, with background winds and tides present, the wind structure is modified above around $120 \mathrm{~km}$. For the zonal wind, eastwards magnitudes generally increase, as the electric field or ion density is increased, and the eastwards wind peak around $140 \mathrm{~km}$, becomes larger. For the meridional wind, the southwards peak around $120 \mathrm{~km}$ becomes larger as the electric field or ion density is increased, but magnitudes above around $150 \mathrm{~km}$ decrease as the electric field or ion density is increased. When the electric field and ion density are enhanced together, as might happen within a strong aurora with large electric fields, the peak wind magnitudes are increased more than when either is enhanced separately. Significant increases in the electric field and ion density enhancement can produce a southwards magnitude peak around 
110 to $120-\mathrm{km}$ altitude as large as that observed, but the strength of the shears above and below the peak are smaller than those observed, and the magnitude of the westwards peak around 110 to $120 \mathrm{~km}$ is still too small relative to the observations. The importance of auroral forcing processes in shaping the neutral wind structure depends on the timing of the introduction of background winds and propagating tides. Background winds and tides, which include a cross arc component, tend to reduce the effectiveness of auroral forcing if they are introduced near the initiation of significant auroral forcing, when the thermosphere has not had much time to respond to the auroral forcing. This is consistent with previous studies which suggest that cross auroral winds reduce the acceleration due to auroral forcing. This is also found to be true when the orientation of the background winds and tides relative to the auroral direction is varied. A combination of auroral forcing and tidal variations in the background winds reproduces the main features of the observed structure, but the very rapid change of magnitude with height found in the strongest shears is not well simulated, and may be related to a currently unmodeled process, or to various types of wave which are not currently simulated.

Acknowledgements. This work was supported by grant ATM0242292 from the National Science Foundation.

Topical Editor U.-P. Hoppe thanks S. Nozawa and another referee for their help in evaluating this paper.

\section{References}

Anderson, P. C., Christensen, A. B., Sharber, J. R., Straus, P. R., Hecht, J. H., Larsen, M. F., Kayser, D. C., McEwen, D. J., Sharp, W. E., Koehler, J. A., Sivjee, G. G., Lyons, L. R., Gutierrez, D. J., and Winningham, J. D.: The ARIA I Rocket Campaign, J. Geophys. Res., 100, 17 265-17 284, 1995.

Bailey, G. J., Balan, N., and Su, Y. Z.: The Sheffield University plasmasphere ionosphere model - a review, J. Atmos. Solar-Terr. Phys., 59, 1541-1552, 1997.

Beard, A. G., Mitchell, N. J., Williams, P. J. S., and Kunitake, M.: Non-linear interactions between tides and planetary waves resulting in periodic tidal variability, J. Atmos. Solar-Terr. Phys., 61, 363-376, 1999.

Brinkman, D. G., Walterscheid, R. L., Lyons, L. R., et al.: E Region Neutral Winds in the Postmidnight Diffuse Aurora During the Atmospheric Response in Aurora I Rocket Campaign, J. Geophys. Res., 100, 17 309-17320, 1995.

Canziani, P. O.: On Tidal Variability and the Existence of Planetary Wave-Like Oscillations in the Upper Thermosphere, 1. Observations of Tidal Variability, J. Atmos. Terr. Phys., 56, 901-912, 1994.

Chapman, S. and Lindzen R.S.: Atmospheric Tides, Thermal and Gravitational, D. Reidel, Dordrecht, Holland, pp. 130-138, 1970.

Chiu, Y. T.: An improved Phenomenological Model of Ionospheric Density, J. Atmos. Terr. Phys., 37, 1563-1570, 1975.
Dao, P. D., Farley, R., Tao, X., and Gardner, C. S.: Lidar Observations of the Temperature Profile Between 25 and $103 \mathrm{~km} \mathrm{-}$ Evidence of Strong Tidal Perturbation, Geophys. Res. Lett., 22, 2825-2828, 1995.

Forbes, J. M. and Vial, F.: Semidiurnal Tidal Climatology of the E-Region J. Geophys. Res., 96 (A2), 1147-1157, 1991.

Forbes, J. M., Jun, G., and Miyahara, S.: On the interactions between Gravity-Waves and the Diurnal Propagating Tide, Plan. Space Sci., 39, 1249-1257, 1991.

Forbes, J. M., Manson, A. H., Vincent, R. A., et al.: Semidiurnal Tide in the 80-150 KM Region - an Assimilative Data-Analysis J. Atmos. Terr. Phys., 56, 1237-1249, 1994.

Forbes, J. M., Makarov, N. A., and Portnyagin, Y. I.: First results from the meteor radar at south pole: A large 12-hour oscillation with zonal wavenumber one Geophys. Res. Lett. Vol. 22, No. 23, 3247-3250, 1995.

Fuller-Rowell, T. J.: A Two-Dimensional, High Resolution, NestedGrid Model of the Thermosphere, 1. Neutral Response to an Electric Field “Spike”, J. Geophys. Res., 89, 2971-2990, 1984.

Fuller-Rowell, T. J.: A Two-Dimensional, High Resolution, NestedGrid Model of the Thermosphere, 2. Response of the Thermosphere to Narrow and Broad Electrodynamic Features, J. Geophys. Res., 90, 6567-6586, 1985.

Fuller-Rowell, T. J., Rees, D., Quegan, S., et al.: Interactions with Neutral Thermospheric Composition and the Polar Ionosphere Using a Coupled Ionosphere-Thermosphere Model, J. Geophys. Res., 92, 7744-7748, 1987.

Hecht, J. H., Walterscheid, R. L., Roble, R. G., Lieberman, R. S., Talaat, E. R., Howat, S. K. R., Lowe, R. P., Turnbull, D. N., Gardner, C. S., States, R., and Dao, P. D.: A comparison of atmospheric tides inferred from observations at the mesopause during ALOHA-93 with the model predictions of the TIME-GCM, J. Geophys. Res., 103, 6307-6321, 1998.

Heppner, J. P. and Maynard, N. C.: Empirical High Latitude Electric Field Models, J. Geophys. Res., 92, 4467-4489, 1987.

Holt, J. M., Wand, R. H., Evans, J. V., et al.: Empirical Models for Plasma Convection at High Latitude from Millstone Hill Observations, J. Geophys. Res., 92, 203-212, 1987.

Isler, J. R. and Fritts, D.: Gravity wave variability and interaction with lower-frequency motions in the mesosphere and lower thermosphere over Hawaii J. Atmos. Sci., 53, 37-48, 1996.

Johnson, R. M., Wickwar, V. B., Roble, R. G., and Luhmann, J. G.: Lower-Thermosphere Winds at High Latitude: Chatanika Radar Observations, Ann. Geophys., 5, 383-404, 1987.

Karpov, I. V.: Mode Structure of Tides in the Lower Thermosphere by Wind Measurements on UARS, Geomag. Aeron., 36, 202206, 1996.

Larsen, M. F.: A Shear Instability Seeding Mechanism for Quasiperiodic Radar Echoes, J. Geophys. Res., 105, 2493124 940, 2000.

Larsen, M. F., Mikkelsen, I. S., Meriwether, J. W., et al.: Simultaneous Observations of Neutral Winds and Electric Fields at Spaced Locations in the Dawn Auroral Oval, J. Geophys. Res., 94, 17 235-17 243, 1989.

Larsen, M. F., Marshall, T. R., Mikkelsen, I. S., et al.: Atmospheric Response in Aurora Experiment: Observations of E and F Region Neutral Winds in a Region of Postmidnight Diffuse Aurora, J. Geophys. Res., 100, 17 299-17 308, 1995.

Larsen, M. F., Christensen, A. B., and Odom, C. D.: Observations 
of Unstable Atmospheric Shear Layers in the Lower E Region in the Postmidnight Auroral Oval, Geophys. Res. Lett., 24, 19151918, 1997.

Larsen, M. F., Fukao, S., Yamamoto, M., Tsunoda, R., Igarashi, K., and Ono, T.: The SEEK Chemical Release Experiment: Observed Neutral Wind Profile in a Region of Sporadic E, Geophys. Res. Lett., 25, 1789-1792, 1998.

Lyons, L. R. and Walterscheid, R. L.: Generation of Auroral Omega Bands by Shear Instability of the Neutral Winds, J. Geophys. Res., 90, 12 321-12 329, 1985.

Manson, A. H., Meek, C., Hagan, M., et al.: Seasonal variations of the semi-diurnal and diurnal tides in the MLT: multi-year MF radar observations from 2-70 deg N, modelled tides (GSWM, CMAM), Ann. Geophys., 20, 661-677, 2002.

Mikkelsen, I. S. and Larsen, M. F.: A Numerical Modeling Study of the Interaction Between the Tides and the Circulation Forced by High-Latitude Plasma Convection, J. Geophys. Res., 96, 12031213, 1991.

Mikkelsen, I. S., Jorgensen, T. S., Kelley, M. C., et al.: Neutral Winds and Electric Fields in the Dusk Auroral Oval, 1. Measurements, J. Geophys. Res., 86, 1513-1524, 1981.

Mikkelsen, I. S., Friis-Christensen, E., Larsen, M. F., Kelley, M. C., et al.: Simultaneous Measurements of the Thermospheric Wind Profile at Three Separate Positions in the Dusk Auroral Oval, J. Geophys. Res., 92, 4639-4648, 1987.

Pancheva, D., Mukhtarov, P., Mitchell, N. J., Beard, A. G., and Muller, H. G.: A Comparative Study of Winds and Tidal Variability in the Mesosphere/Lower-Thermosphere Region Over Bulgaria and the UK, Ann. Geophys., 18, 1304-1315, 2000.

Pancheva, D., Mitchell, N. J., Manson, A. H., Meek, C. E., Jacobi, C., Portnyagin, Y., Merzlyakov, E., Hocking, W. K., MacDougall, J., Singer W., et al.: Variability of the quasi-2-day wave observed in the MLT region during the PSMOS campaign of June-August 1999, J. Atmos. and Solar-Terr. Phys., 66, 539-565, 2004.

Parish, H. F., Fuller-Rowell, T. J., Rees, D., Virdi, T. S., and Williams, P. J. S.: Numerical Simulations of the Seasonal Response of the Thermosphere to Propagating Tides, Adv. Space Res., 10, 287-291, 1990.

Parish, H. F., Gladstone, G. R., and Chakrabarti, S.: Interpretation of Satellite Airglow Observations During the March 22, 1979, Magnetic Storm, Using the Coupled Ionosphere-Thermosphere Model Developed at University College London, J. Geophys. Res., 99, 6155-6166, 1994.

Parish, H. F, Robinson, T. R., Stocker, A. J., and Jones, T. B.: Evidence of Gravity Wave Structures in CUTLASS Radar Measurements, Adv. Space Res., 20, 1257-1260, 1997.
Parish, H. F., Walterscheid, R. L., Jones, P. W., and Lyons, L. R.: Simulations of the Thermospheric Response to the Diffuse Aurora Using a Three-Dimensional High Resolution Model, J. Geophys. Res., 108(A4),1140, doi:10.1029/2002JA009610, 2003.

Phillips, A. and Briggs, B. H.: The day-to-day Variability of Upper Atomsphere Tidal Winds and Dynamo Currents, J. Atmos. Terr. Phys., 53, 39-47, 1991.

Portnyagin, Y. I., Forbes, J. M., Makarov, N. A., Merzlyakov, E. G., and Palo, S.: The summertime 12-h wind oscillation with zonal wavenumber $\mathrm{s}=1$ in the lower thermosphere over the South Pole, Ann. Geophys., 16, 828-837, 1998.

Richmond, A. D. and Matsushita, S.: Thermospheric Response to a Magnetic Substorm, J. Geophys. Res., 80, 2839-2850, 1975.

St.-Maurice, J.-P. and Schunk, R. W.: Ion-Neutral Momentum Coupling Near Discrete High-Latitude Ionospheric Features, J. Geophys. Res., 80, 11 299-11321, 1981.

Walterscheid, R. L. and Lyons, L. R.: The Neutral E Region Zonal WInds During Intense Postmidnight Diffuse Aurora: Response to Observed Particle Fluxes, J. Geophys. Res., 94, 3703-3712, 1989.

Walterscheid, R. L., Lyons, L. R., and Taylor, K. E.: The Perturbed Neutral Circulation in the Vicinity of a Symmetric Stable, J. Geophys. Res., 90, 12 235-12 248, 1985.

Wang, C.-P., Lyons, L. R., Chen, M. W., and Wolf, R. A.: Modeling the Quiet Time Inner Plasma Sheet Protons, J. Geophys. Res., 106, 6161, (2000JA000377), 2001.

Weimer, D. R.: Models of High-Latitude Electric Potentials Derived with a Least Error Fit of Spherical Harmonic Coefficients, J. Geophys. Res., 100, 19 595-19608, 1995.

Weimer, D. R.: A Flexible, IMF Dependent Model of High-Latitude Electric Potentials Having Space Weather Applications, Geophys. Res. Lett., 23, 2549-2552, 1996.

Weimer, D. R.: An improved model of ionospheric electric potentials including substorm perturbations and application to the Geospace Environment Modeling November 24, 1996, event, J. Geophys. Res., 106, 407, doi:10.1029/2000JA000604, 2001.

Wing, S. and Newell, P. T.: Central Plasma Sheet Ion Properties as Inferred from Ionospheric Observations, J. Geophys. Res., 103, 6785, doi:10.1029/97JA02994, 1998.

Yamamoto, M., Ono, T., Oya, H., Tsunoda, R. T., Larsen, M. F., Fukao, S., and Yamamoto, M.: Structures in Sporadic-E Observed with an Impedance Probe During the SEEK Campaign: Comparisons with Neutral-Wind and Radar-Echo Observations, Geophys. Res. Lett., 25, 1781-1784, 1998.

Zhang, S. P. and Shepherd, G. G.: Variations of the mean winds and diurnal tides in the mesosphere and lower thermosphere observed by WINDII from 1992 to 1996, Geophys. Res. Lett., 32, L14111, doi:10.1029/2005GL023293, 2005. 